\title{
INTEGRATED MODEL OF MODELS FOR GLOBAL FLOOD ALERTING
}

\author{
BANDANA KAR ${ }^{1}$, DOUG BAUSCH${ }^{2}$, JUN WANG ${ }^{3}$, PRATIVA SHARMA ${ }^{4}$, ZHIQIANG CHEN $^{4}$, \\ GUY SCHUMANN ${ }^{5}$, MARLON PIERCE ${ }^{3}$, KRISTY TIAMPO $^{6}$, RON EGUCHI $^{7}$ \& MARGARET GLASSCOE ${ }^{8}$ \\ ${ }^{1}$ Oak Ridge National Laboratory, USA \\ ${ }^{2}$ Pacific Disaster Center, USA \\ ${ }^{3}$ Indiana University, USA \\ ${ }^{4}$ University of Missouri, USA \\ ${ }^{5}$ Dartmouth Flood Observatory, USA \\ ${ }^{6}$ University of Colorado, USA \\ ${ }^{7}$ ImageCat Inc., California, USA \\ ${ }^{8}$ Jet Propulsion Laboratory, California Institute of Technology, USA
}

\begin{abstract}
A dramatic increase in frequency of minor to major flooding since 2000 has caused significant economic losses across the world. To mitigate and recover from these losses, actions have been taken to build resilient communities and infrastructures, specifically, by providing situational awareness in near real-time about flood impacts to enhance response and recovery efforts. Several hydrologic and hydraulic flood models are available at various spatial and temporal resolutions to forecast flood events at regional to global scale. Given the global coverage of two operational flood models - GloFAS (Global Flood Awareness System) and GFMS (Global Flood Monitoring System), the purpose of this project is to implement a Model of Models (MoM) approach to integrate the outputs from these two models to classify flood severity at watershed level worldwide, and send alerts based on severity similar to the USGS PAGER (used for severity alerting and impact analysis for earthquakes) to flood impacted communities. The alerts containing flood impacts and severity information will be disseminated through the DisasterAWARE platform, operated by the Pacific Disaster Center (PDC), that provides global multi-hazard alerting and Situational Awareness information to the emergency management community and public. The current version of the MoM approach was implemented for a case study flood event that occurred during January and February of 2020 in South and Central Africa. The findings of the case study event reveal that the approach is effective in identifying potential flood impact areas and the spatio-temporal variation of flood severity, flood depth and extent at watershed level, which will be used to assess infrastructure and societal impacts using earth-observation data and for alerting. Keywords: global flood forecasting, flood modelling, model of models, alerting, DisasterAWARE.
\end{abstract}

\section{INTRODUCTION}

Flooding is one of the most frequent natural hazards worldwide. Extreme rainfall induced by rapid urbanization and climatic change have contributed to severe flood events, along with significant societal and economic impacts worldwide [1]-[4]. According to the international disaster database (EMDAT) [5], 2019 saw more than 120 floods globally of varying intensity and since 2000, on average, 100 floods annually have occurred worldwide (Fig. 1(a)) that have caused about $\$ 10$ billion (USD) financial loss per annum (Fig. 1(b)) and significant number of deaths with Asia experiencing the maximum number of fatalities (Fig. 1(c)).

Significant efforts have been made over the past few decades to increase community resilience to flooding and for flood risk management by improving flood risk mapping [6] and forecasting [7], flood impact assessment [8], and floodplain ecology and catchment hydrology [9]. Similar efforts have been made to improve the numerical methods used for flood modelling and use of parallel computing technologies to enhance flood modelling [10]. Irrespective of these modelling advancements, there exists two types of models: (i) empirical and (ii) hydrodynamic [11]. 


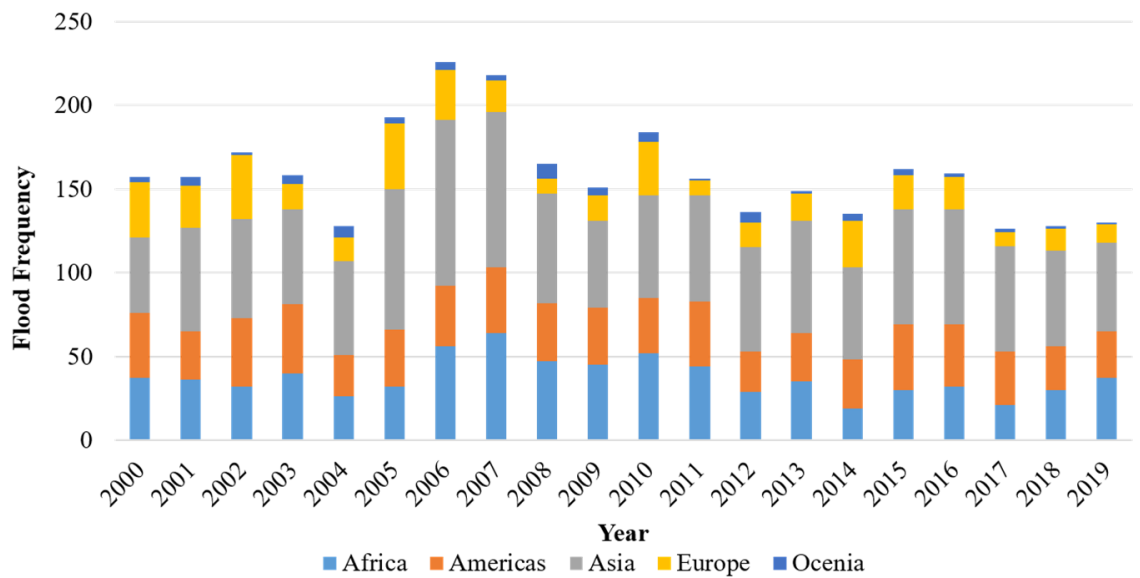

(a)

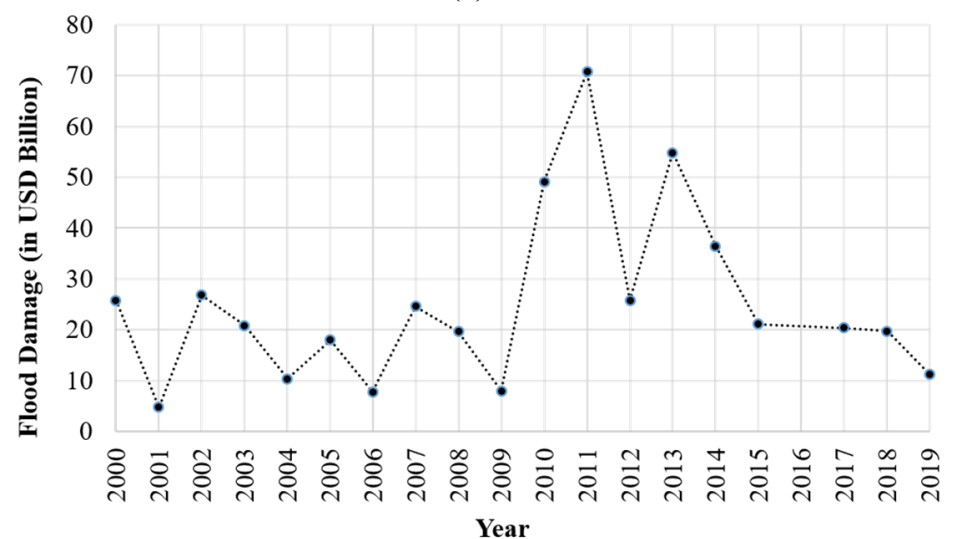

(b)

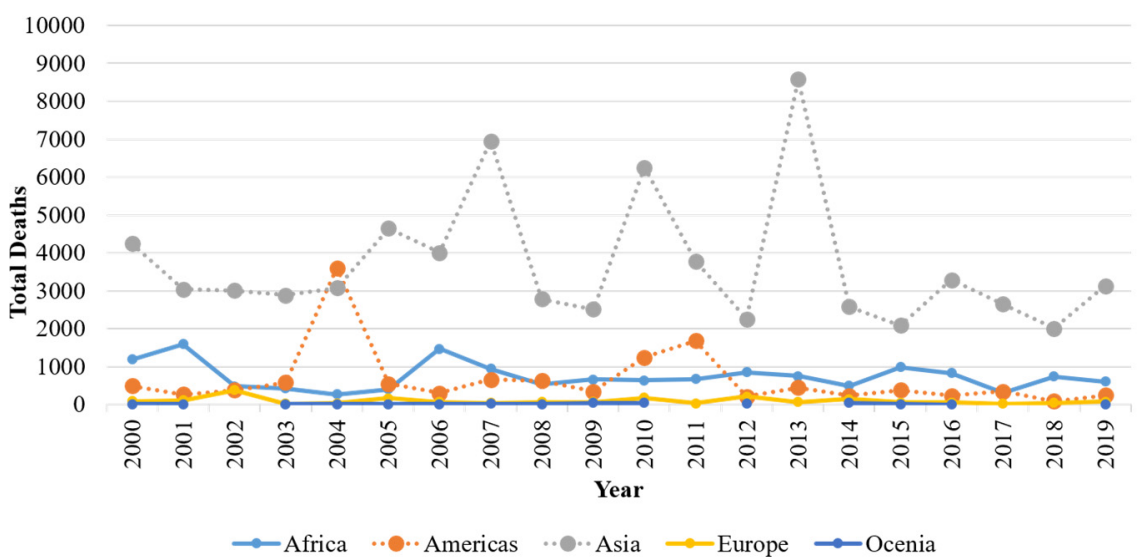

(c)

Figure 1: Global flood statistics 2000-2019. (a) Annual flood frequency; (b) Annual flood induced financial damage; (c) Annual flood induced mortalities. (Source: Université Catholique de Louvain [5].) 
Empirical models are data driven and developed using historical flood observations, on-ground measurements, surveys, satellite imageries, etc. [11]. Given the nature of inputs used in these models, they are often used for calibration and validation of hydrodynamic models and contain uncertainties. Alternatively, hydrodynamic models are mathematical models that replicate fluid motion of water by accounting for water volume, runoff and soil absorption, topographic conditions, among other things. These models can be one, two and three dimensional depending upon the spatial representation of the flood plain and flood water flow. Because a discussion of these models is beyond the scope of this paper, please refer to Teng et al. [11] for a review of the models.

While empirical models are straightforward, their accuracy is impacted by the spatial and temporal resolutions of the input data, sensor design requirements, environmental factors (cloud cover, weather conditions) as well as statistical approaches used to process the data [11]. By contrast, hydrodynamic models are widely used due to their accurate representation of flood extent and depth. Nonetheless, these models suffer from uncertainties resulting from 1-D, 2D and 3D representation of flood plain and water flow, the input variables and physics used for the models, and the spatio-temporal resolutions of the data sets.

To mitigate and recover from flood induced losses, it is essential to provide situational awareness information to impacted communities in near real-time to aid them with response and recovery efforts, thereby enhancing their resilience. While significant number of flood models are available, these models vary in approach, data and output as well as are implemented at regional to global scale as discussed above. The purpose of this study is to develop and deploy a Model of Models (MoM) approach that integrates two globally operationally flood models - GloFAS (Global Flood Awareness System) and GFMS (Global Flood Monitoring System) - to classify flood severity and send alerts based on severity level to impacted communities similar to USGS PAGER (used for severity alerting and impact analysis for earthquakes) using Pacific Disaster Center's (PDC) DisasterAWARE platform.

The remainder of this paper is organized into five sections. The second section provides a discussion of the DisasterAWARE platform, which is followed by the methodology section that describes the MoM approach used to integrate GloFAS and GFMS and determine flood severity for alerting. The fourth section discusses a case study implementation of the MoM approach using the African flooding that occurred during January-February 2020. The results of the case study are presented and discussed in the fifth section following which the conclusion and future research directions are presented.

\section{DISASTER-AWARE PLATFORM}

DisasterAWARE $^{\mathrm{TM}}$ is a system maintained by PDC at University of Hawaii. This system provides multi-hazard warning and situational awareness information for decision support through mobile apps and web-based platforms to millions of users worldwide. Operational version of DisasterAWARE ${ }^{\mathrm{TM}}$ is used by multiple national and international agencies including UN agencies for emergency management.

This system continually monitors reliable scientific data sources for events deemed potentially hazardous to people, property, or assets, and posts these incidents as "Active Hazard Alerts." These postings are accessible to decision makers and to the public through early warnings and decision support tools. These Active Hazard Alerts are also available through a Disaster Alert System (DAS) for real-time notifications where users indicate their areas of interest, hazard types and severity for which they would like to receive alerts. While the system provides alerting, severity and decision support for 18 hazard types, potential impact and severity information are provided only for a few hazards (e.g. earthquake, volcano, tropical cyclone) at global scale. 
Flooding is a common extreme event, which is also the deadliest as discussed above. However, currently, the DisasterAWARE ${ }^{\mathrm{TM}}$ system lacks global flood alerting and does not incorporate a remote sensing component for ground truthing that will allow near real-time validation of flood model prediction outputs. This research focuses on leveraging publicly available and widely used global flood models to determine flood severity.

\section{METHODOLOGY}

To generate an open-access rapid alerting and severity assessment component for global flooding for DisasterAWARE ${ }^{\mathrm{TM}}$, a MoM approach is implemented, which integrates existing flood models rather than creating new models. The main features of this model are to: (i) integrate forecasted flood extent and depth information along with flood severity from GloFAS and GFMS, (ii) determine the risk of an area experiencing flood based on severity at global watershed level, (iii) integrate remote sensing observations for validation and calibration of MoM outputs so that actionable knowledge can be generated for decision making. In the following sub-sections, a discussion of GloFAS and GFMS along with the flood severity assessment at watershed level is presented.

\subsection{Global Flood Awareness System (GloFAS)}

The GloFAS system is a global hydrological forecast and monitoring system independent of administrative and political boundaries that is jointly developed by the European Commission and the European Centre for Medium-Range Weather Forecasts (ECMWF) [12]. The system couples state-of-the art weather forecasts with a hydrologic model to provide downstream countries with information on upstream river conditions. GloFAS produces daily flood forecasts and monthly seasonal streamflow outlooks (Fig. 2).
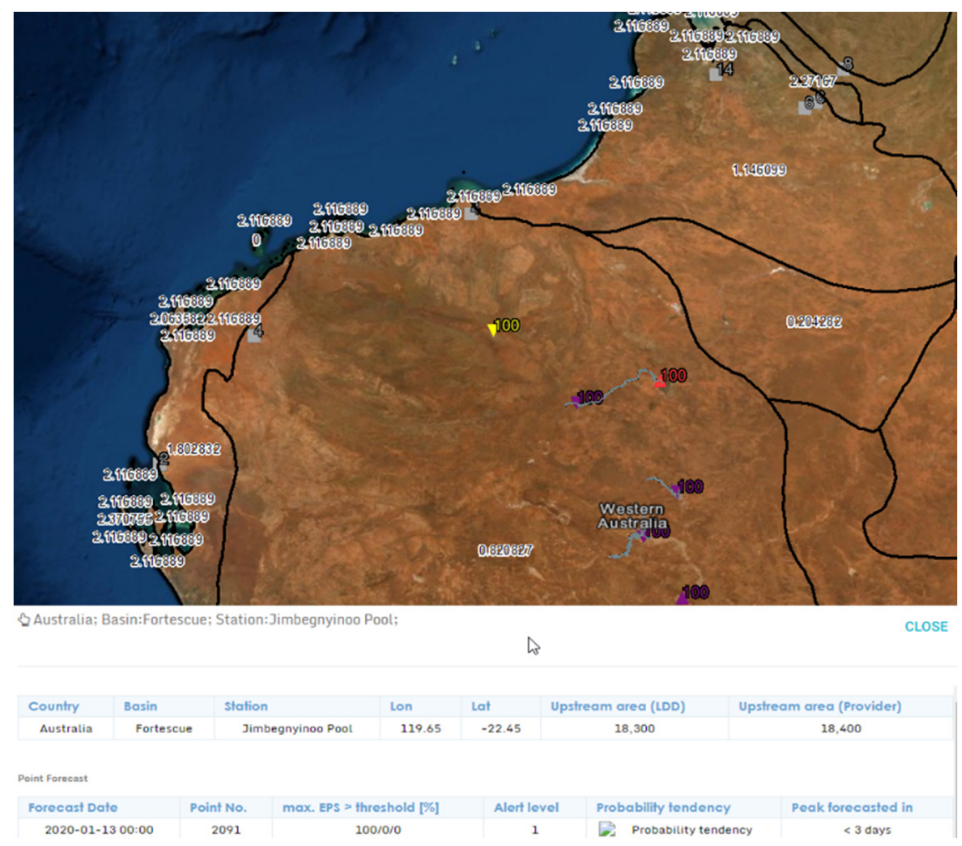

Figure 2: Output from Global Flood Awareness System. (Source: European Commission Copernicus Emergency Management Service [12].) 
For the MoM approach, the following hazard severity indicators are obtained from GloFAS: probability of return period events (2, 5 and 20 year), alert level (Medium, High, Severe) and peak forecast (days).

\subsection{Global Flood Monitoring System (GFMS)}

The GFMS uses real-time precipitation information from Tropical Rainfall Measuring Mission (TRMM) Multi-satellite Precipitation Analysis (TMPA) and implements a hydrologic runoff and routing model to produce flood detection/intensity estimates [13]. The system is functional at a quasi-global $\left(50^{\circ} \mathrm{N}-50^{\circ} \mathrm{S}\right)$ scale and the hydrologic model is implemented at a $1 / 8$ th degree latitude/longitude grid. The flood detection/intensity estimates are based on 13 years of retrospective model runs with TMPA input while flood thresholds are derived at each grid location using surface water storage statistics (95th percentile plus parameters related to basin hydrologic characteristics) (Fig. 3). The model generates streamflow, surface water storage, inundation variables at $1 \mathrm{~km}$ resolution as well as instantaneous precipitation, and totals from the last day, three days and seven days. For integration in MoM, the following indicators from GFMS are extracted at every 3-hour interval at 0.125 degree grid resolution: size (area and \% area in a watershed impacted by a flood), depth above baseline (mean and max) and duration (days).

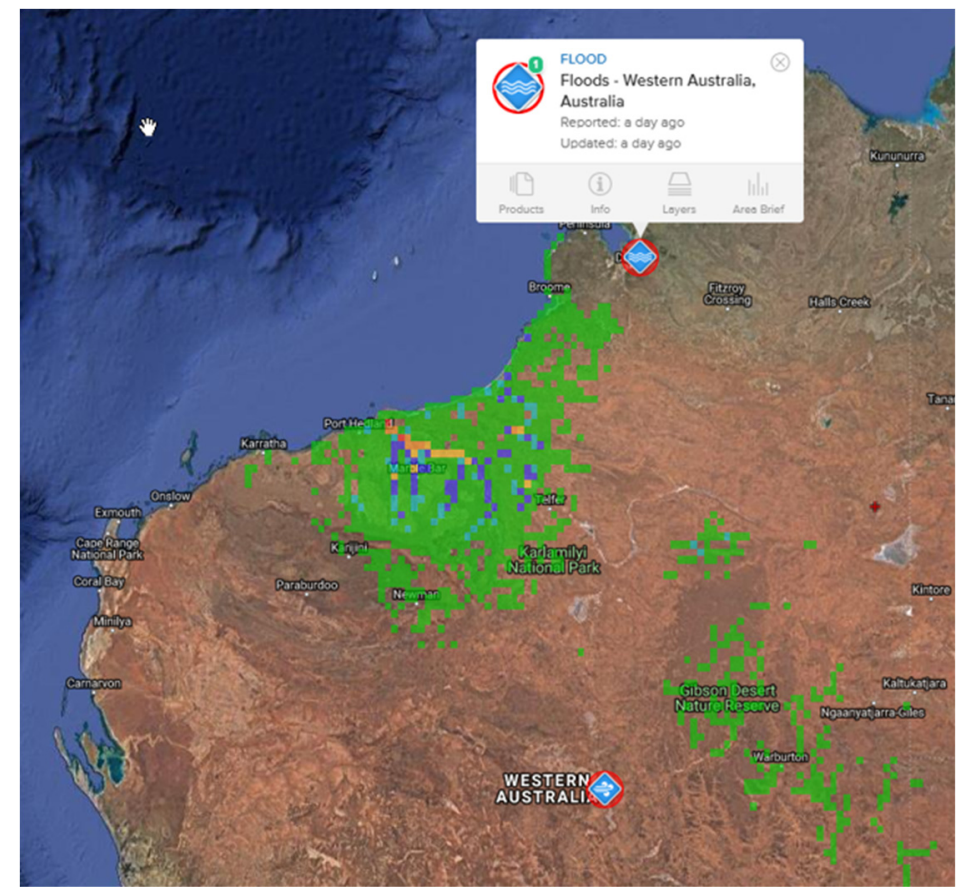

Figure 3: Global Flood Monitoring System. (Source: University of Maryland [13].)

\subsection{Watershed risk index}

For the purpose of global flood severity assessment, the outputs from both GloFAS and GFMS are integrated at a static watershed level. The watershed boundaries are based on 
hazards rather than political boundaries, which helps generate flood severity and impact information for an entire watershed and population impacted by the flood within the watershed to be used by stakeholders.

Although several watershed datasets are available, the World Resources Institute (WRI) product is used along with the MoM approach as it provides both the geometry information and flood risk attributes (WRI, 2019) for $\sim 3,400$ basins across the world. WRI incorporates both the flood risk and drought risk information as well as the baseline and projected future conditions. The following flood risk related attributes are used to determine flood severity at watershed level: Riverine flood risk (rfr_score) and Coastal flood risk (cfr_score).

\subsection{MoM implementation}

The MoM approach implements a cumulative distribution function (CDF) (Fig. 4) to combine the hazard scores determined by integrating GloFAS and GFMS outputs with risk scores at watershed level to compute flood hazard severity at the watershed level. For MoM implementation, first, a weighting approach is used to combine the hazard severity indicators from each model (GloFAS and GFMS) to determine hazard score that ranges between $0-100$ (100 being highest score). Second, the watershed risk score ( $\mathrm{rfr}$ score or cfr_score) is rescaled from $0-5$ to $0-100$. Finally, the risk at watershed level and hazard score from the flood models are combined using a CDF to determine the probability of flood at each watershed, which is used to determine dissemination of alert messages based on certain threshold. For instance, based on the probability (derived by using CDF in Fig. 4), a warning will be sent at $75 \%-100 \%$, a watch advisory will be sent at $50 \%-75 \%$, an advisory will be disseminated at $25 \%-50 \%$ and just information will be sent at $<25 \%$.

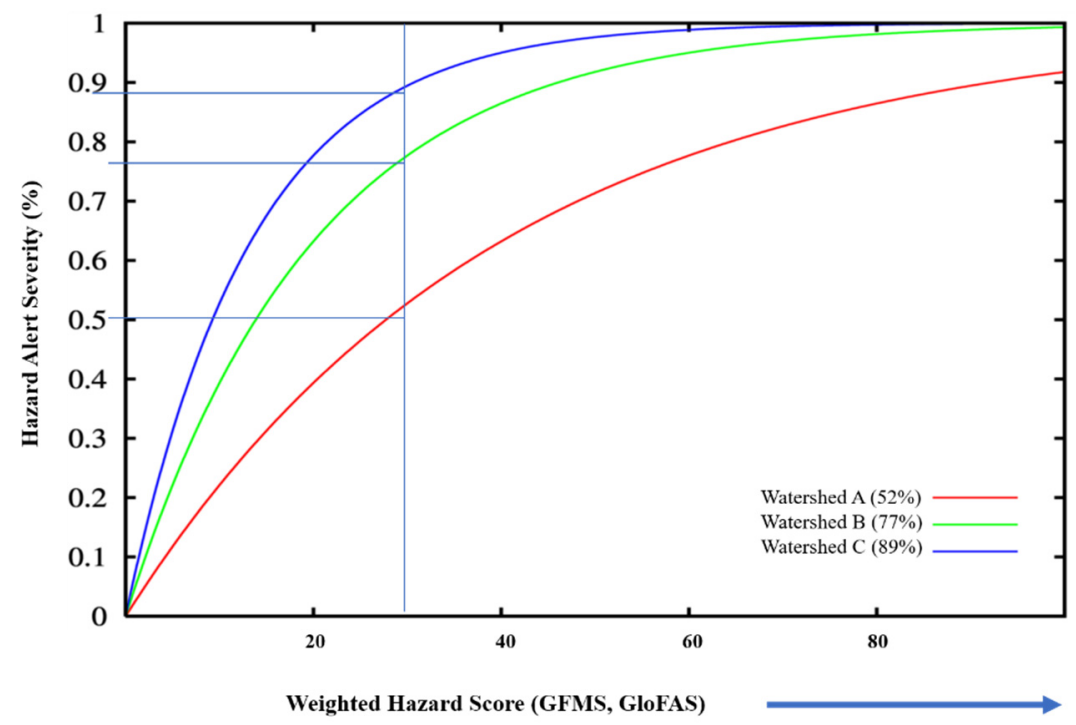

Figure 4: Watershed risk based on cumulative distribution function.

\section{CASE STUDY}

The MoM approach was implemented for a case study flood event that occurred in early 2020 in Africa. During January and February of 2020, significant number of floods have impacted 
the African continent [14]. These events have been severe as they have caused a number of fatalities and homelessness in different parts of Africa (Madagascar, Tanzania, Zimbabwe, among others). From emergency management perspective, it is crucial to provide flood alerts for these deadly events to communities in near real-time to aid with evacuation and other response activities. A discussion of the steps implemented to determine flood severity of the African countries using MoM approach on 11th February 2020 is presented below.

\subsection{Data processing and analysis}

For the African flood, the flood depth above threshold (in $\mathrm{mm}$ ) data were obtained from the GFMS site in binary raster format with 4-byte float type for every 3-hour time step and $0.125^{\circ}$ spatial resolution. Using the dimension and geo-reference information for the grids (e.g., row $=800, \mathrm{col}=2458$, xllcorner $=-127.25$, yllcorner $=-50$ cellsize $=0.125$ and, NoDat $\mathrm{a}=-9999$ ), header files were created for each binary file, which were then used to create Virtual Raster Datasets (readable format within GDAL library). The raster layers and the watershed boundary files were converted to EPSG:3857 WGS84 Web Mercator (Auxiliary Sphere) spatial reference system following which Zonal statistics were performed using watershed boundaries on these raster layers to obtain - flooded area $\left(\mathrm{km}^{2}\right)$, percentage flooded area (flooded area/watershed area), maximum and minimum flood depth above threshold (mm), and time stamp of flood occurrence.

Flood data for the same event were obtained from GloFAS using its Web Map Service. The output contained points (gage stations) within a specific watershed with the following attributes - country name, watershed basin, station location, upstream area, alert level, peak forecasted days, probability of threshold exceedance based on $2 \mathrm{yr}, 5 \mathrm{yr}$ and $20 \mathrm{yr}$ forecasted thresholds. Using Python/GDAL, steps were implemented to automate data download from both flood models.

\subsection{Flood severity estimation}

To estimate flood severity (in percent probability) for the African countries and watersheds, the following steps were implemented:

1. The GloFAS outputs for 11th February 2020 (Alert level, Peak forecast, GloFAS_2yr, GloFAS_5yr, GloFAS_20yr) were rescaled between 1-10 using Table 1.

2. The GFMS outputs for 11 th February 2020 (area, $\%$ watershed area, mean and maximum depth, and duration (hours the watershed was flooded)) were rescaled between 1-10 as per the weighting scheme for each interval. Because GFMS outputs were generated at 3$\mathrm{hr}$ interval, weighted averages were computed for each output.

3. The weighted indicators were summed together to determine weighted hazard score for impacted watersheds in Africa. The riverine flood risk of each watershed was scaled between 0-100 and incorporated PDC's lack of resilience parameter to identify watersheds with high risk for flood loss due to low resilience.

4. The weighted hazard score (from flood models) was integrated with scaled riverine flood risk at watershed level using CDF to compute severity score (percent probability of experiencing severe flood) (Fig. 5).

5. The computed severity score - a representation of the probability of severe flood impacts - was used to identify watersheds that were at a higher risk of experiencing flooding. The severity score was also classified to identify when alerts and warnings will be disseminated for preparedness and response activities. 
Table 1: Weighting scheme for hazard severity indicators.

\begin{tabular}{|c|c|c|}
\hline Field & Description & Initial weighting \\
\hline GFMS_TotalArea_km & Total impact area in watershed & $\begin{array}{l}1 \mathrm{pt} \text { for every } 100 \mathrm{sqkm}, \max = \\
10(\text { e.g. } 890 \mathrm{sq} \mathrm{km}=8.9)\end{array}$ \\
\hline GFMS \%Area & GFMSArea/WatershedArea & $\% 100 / 10($ e.g. $66 \%=6.6)$ \\
\hline GFMS_MeanDepth & Mean depth in watershed in $\mathrm{mm}$ & $\begin{array}{l}1 \mathrm{pt} \text { for every } 10 \mathrm{~mm}, \max 10 \\
\text { (e.g. } 56 \mathrm{~mm}=5.6)\end{array}$ \\
\hline GFMS_MaxDepth & Max depth in watershed in $\mathrm{mm}$ & $\begin{array}{l}1 \mathrm{pt} \text { for every } 100 \mathrm{~mm}, \max = \\
10(\text { e.g. } 890 \mathrm{~mm}=8.9)\end{array}$ \\
\hline GFMS_Duration & $\begin{array}{l}\text { Number of 3-hr intervals a specific } \\
\text { area has been flooded (at least } 100 \\
\text { square km overlap in each interval) }\end{array}$ & $\begin{array}{l}\text { Continuous days of at least } \\
100 \text { sq km overlap, } 1 \text { per day, } \\
\text { max } 10 \text { (e.g. } 66 \text { hours }=2.75)\end{array}$ \\
\hline GloFAS_20yr\% & $\begin{array}{l}\text { EPS threshold \% based on 3rd entry } \\
\text { (e.g. } 86 / 53 / 22=22 \% \text { ) }\end{array}$ & $\% 100 / 10($ e.g. $66 \%=6.6)$ \\
\hline GloFAS_5yr\% & $\begin{array}{l}\text { EPS threshold } \% \text { based on } 2 \text { nd entry } \\
\text { (e.g. } 86 / 53 / 22=53 \% \text { ) }\end{array}$ & $\% 100 / 10($ e.g. $66 \%=6.6)$ \\
\hline GloFAS_2yr\% & $\begin{array}{l}\text { EPS threshold } \% \text { based on } 1 \text { st entry } \\
\text { (e.g. } 86 / 53 / 22=86 \%)\end{array}$ & $\% 100 / 10($ e.g. $66 \%=6.6)$ \\
\hline GloFAS_AlertLevel & Alert Level $1-3$ with 3 greatest value & Level *3, max $10($ e.g. $3=9)$ \\
\hline GloFAS_PeakForecasted & $\begin{array}{l}\text { Number of days until peak forecast } \\
\text { arrives at observation point }\end{array}$ & $\begin{array}{l}\text { Weight in days where } 1=10, \\
2=9, \ldots 10 \text { or greater }=1\end{array}$ \\
\hline Dynamic hazard score & $\begin{array}{l}\text { Updated every } 3 \text { hours based on } \\
\text { GFMS and } 24 \text { hours based on } \\
\text { GloFAS }\end{array}$ & $0-100$ sum of hazard inputs \\
\hline
\end{tabular}

\section{RESULTS AND DISCUSSION}

Fig. 5 depicts the distribution of the severity score for eight countries in South-Central Africa. Based on the precipitation volume, it is evident from the figure that the Democratic Republic of the Congo (DRC) and Mozambique were the two countries with high risk of experiencing severe flood. According to the PDC's lack of resilience indicators, these two countries also do not have significant resilience initiatives in place, which makes them more susceptible to experiencing significant financial and societal losses from this flood event and future flood events if they occur after February 2020.

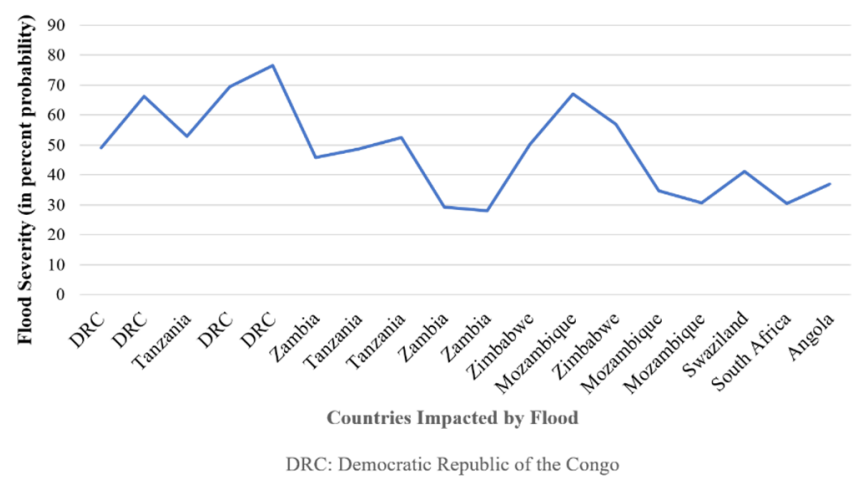

Figure 5: Flood severity score of South and Central African countries on 11th February 2020. 
Fig. 6 displays the spatial distribution of the impacted countries and their associated watersheds. Evidently, not all watersheds within a country have similar severity. For instance, the watersheds in DRC have a moderate to very high probability of experiencing severe flood and they also need to receive warnings to prepare for the event. All watersheds in Zambia, Zimbabwe, Tanzania and Mozambique have moderate to high severity, and watersheds in the remaining countries - Angola, South Africa, Swaziland have moderate severity. This severity score is dynamic, which will change with increasing precipitation and flooding, and therefore, can be used to disseminate alerts or watches to these countries in real-time with progress of future floods to help with emergency management efforts.

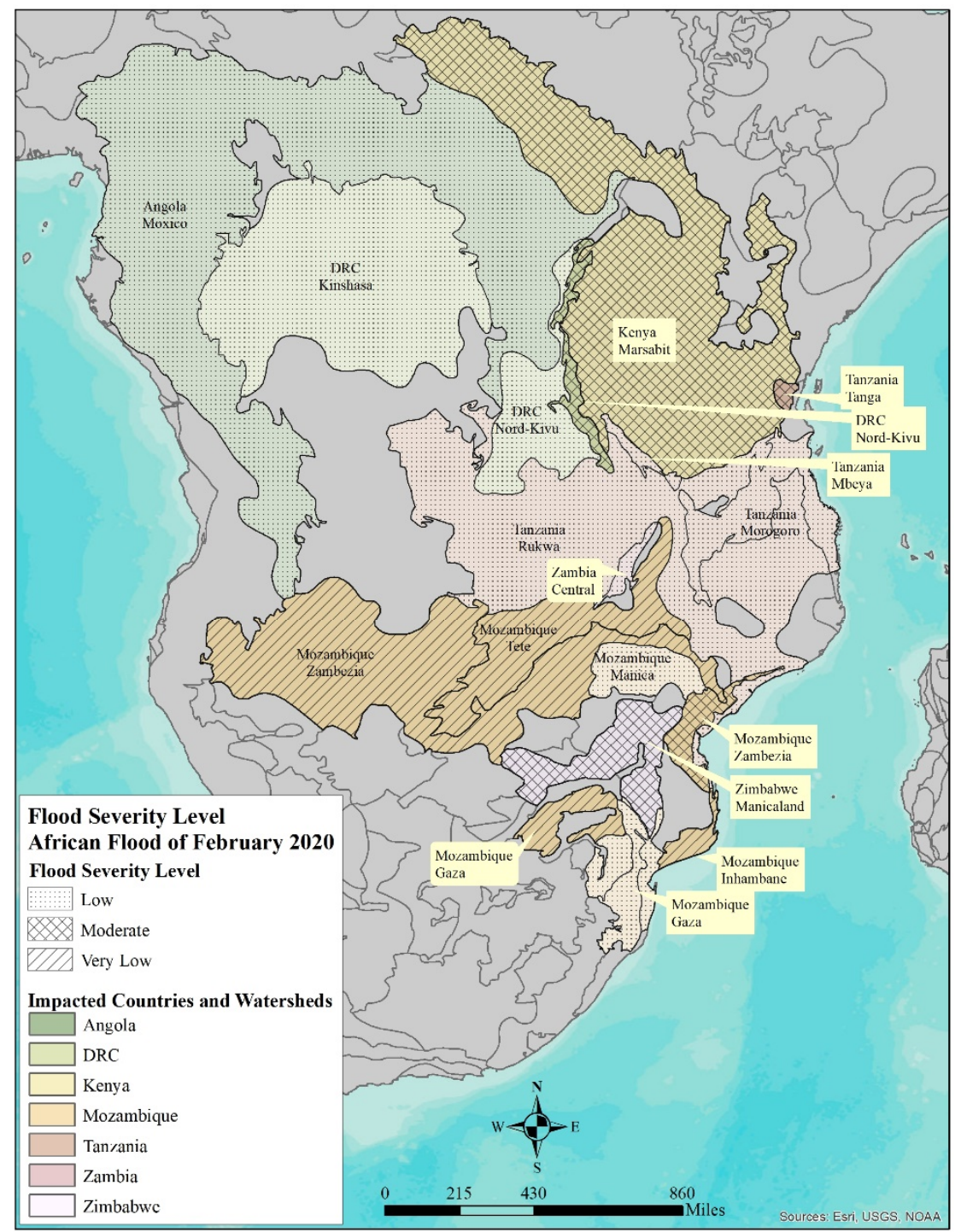

Figure 6: Flood severity score for South and Central African countries and corresponding watersheds on 11th February 2020. 


\section{CONCLUSION AND FUTURE DIRECTION}

Despite the availability of several flood models, the lack of consistency in inputs, outputs, scale of analysis and resolution of data sets as well as the models used to represent terrain and waterflow contributes to generating varying flood outputs to be useful across a broad range of applications. As an alternative, in this project we implemented a MoM approach that integrated the output of real-time flood models at a global scale that has wide application. Evidently, the MoM approach is effective in forecasting flood extent and depth as well as in determining flood severity in impacted areas such that alerts can be disseminated in real-time to impacted communities.

According to the MoM approach, most of the countries in South and Central Africa have moderate to very high severity, which means these countries are at high risk of experiencing severe flood. With continuous precipitation and lack of resilience initiatives in these countries, it can be expected that these countries will experience significant flood induced damages and financial losses, and subsequently, longer time to recover. However, the output of the MoM approach can be used to disseminate alerts and warnings ahead of time to stakeholders and local communities in these countries to prepare effective strategies to mitigate flood induced losses.

In the current implementation of the MoM approach, the weighting scheme was implemented by using the attributes that impact flood severity. In future, a spatial implementation of the weighting scheme using Multi-Criteria Decision Analysis (MCDA) will be conducted that will also account for the time series distribution of the model outputs. The MCDA based weighted approach will ensure that the temporal variation of flooding is accounted for such that the areas experiencing heavy precipitation are weighted highly, thereby increasing their severity and probability of experiencing heavy flood and significant loss. In the current approach, an average was computed for flood severity indicators over a 24-hr period using 3-hr interval GFMS outputs. In future, a spatio-temporal weighting will be implemented to ensure that the flood severity varies for different locations within a watershed across different time span to make flood severity estimation more granular. Finally, flood extent and depth derived from satellite imagery and Digital Elevation Model will be used to validate and calibrate MoM outputs. The validated and calibrated outputs will then be used to estimate flood induced damages, impacted population and losses.

\section{ACKNOWLEDGEMENTS}

The research was carried out at the Jet Propulsion Laboratory, California Institute of Technology, under a contract with the National Aeronautics and Space Administration (80NM0018D0004). This manuscript has been authored by UT-Battelle, LLC under Contract No. DE-AC05-00OR22725 with the U.S. Department of Energy. The U.S. Government retains and the publisher, by accepting the article for publication, acknowledges that the U.S. Government retains a non-exclusive, paid-up, irrevocable, world-wide license to publish or reproduce the published form of this manuscript, or allow others to do so, for United States Government purposes. The findings and opinions presented in this manuscript are those of the authors, and do not reflect the policy or position of any of the aforementioned institutions.

\section{REFERENCES}

[1] Curebal, I., Efe, R., Ozdemir, H., Soykan, A. \& Sönmez, S., GIS-based approach for flood analysis: Case study of Keçidere flash flood event (Turkey). Geocarto International, 31(4), pp. 355-366, 2016. 
[2] Korichi, K., Hazzab, A. \& Atallah, M., Flash floods risk analysis in ephemeral streams: A case study on Wadi Mekerra (northwestern Algeria). Arabian Journal of Geoscience, 9(11), p. 589, 2016.

[3] Yang, L. et al., Structure and evolution of flash flood producing storms in a small urban watershed. Journal of Geophysical Research: Atmosphere, 121(7), pp. 3139-3152, 2016.

[4] Yin, J., Yu, D., Yin, Z., Liu, M. \& He, Q., Evaluating the impact and risk of pluvial flash flood on intra-urban road network: A case study in the city center of Shanghai, China. Journal of Hydrology, 537, pp. 138-145, 2016.

[5] Université Catholique de Louvain (UCL) - CRED, EMDAT: The Emergency Events Database. www.emdat.be/. Accessed on: 23 Feb. 2020.

[6] Dutta, D., Herath, S. \& Musiake, K., An application of a flood risk analysis system for impact analysis of a flood control plan in a river basin. Hydrological Processes, 20(6), pp. 1365-1384, 2006.

[7] Arduino, G., Reggiani, P. \& Todini, E., Recent advances in flood forecasting and flood risk assessment. Hydrology and Earth System Science, 9(4), pp. 280-284, 2005.

[8] Bhuiyan, M. \& Dutta, D., Analysis of flood vulnerability and assessment of the impacts in coastal zones of Bangladesh due to potential sea-level rise. Natural Hazards, 61(2), pp. 729-743, 2012.

[9] Karim, F. et al., Assessing the impacts of climate change and dams on floodplain inundation and wetland connectivity in the wet-dry tropics of northern Australia. Journal of Hydrology, 522, pp. 80-94, 2015.

[10] Vacondio, R., Aureli, F., Ferrari, A., Mignosa, P. \& Dal Palù, A., Simulation of the January 2014 flood on the Secchia River using a fast and high-resolution 2D parallel shallow-water numerical scheme. Natural Hazards, 80(1), pp. 103-125, 2016.

[11] Teng, J., Jakeman, A.J. \& Croke, B., Flood inundation modelling: A review of methods, recent advances and uncertainty analysis. Environmental Modeling and Software, 90, pp. 201-216, 2017.

[12] European Commission Copernicus Emergency Management Service, The Global Flood Awareness System - GloFAS - in a nutshell. www.globalfloods.eu/. Accessed on: 23 Feb. 2020.

[13] University of Maryland, Global Flood Monitoring System. http://flood.umd.edu/. Accessed on: 23 Feb. 2020.

[14] FloodList, European system for earth monitoring. http://floodlist.com/africa. Accessed on: 23 Feb. 2020. 